\title{
Neurocisticercosis cerebral asociada a meningioma
}

\author{
José Luis Alcocer-Maldonado, ${ }^{1}$ Luis Gerardo Domínguez-Carrillo ${ }^{2}$
}

Masculino de 40 años de edad que presenta crisis convulsiva de inicio focal que afecta el hemicuerpo izquierdo, de dos meses de evolución, y cefalea frontal bilateral de predominio nocturno que no mejora con analgésicos. En la exploración, se observa alerta, con edema papilar bilateral; paresia facial central izquierda y hemiparesia izquierda con signos de Babinski y Hoffman; reflejos osteotendinosos ipsilaterales aumentados. En la tomografía axial computarizada de cráneo simple (Figura 1) se detectan cisticercos y lesión parietal derecha de 5 × 4 centímetros, la cual refuerza con

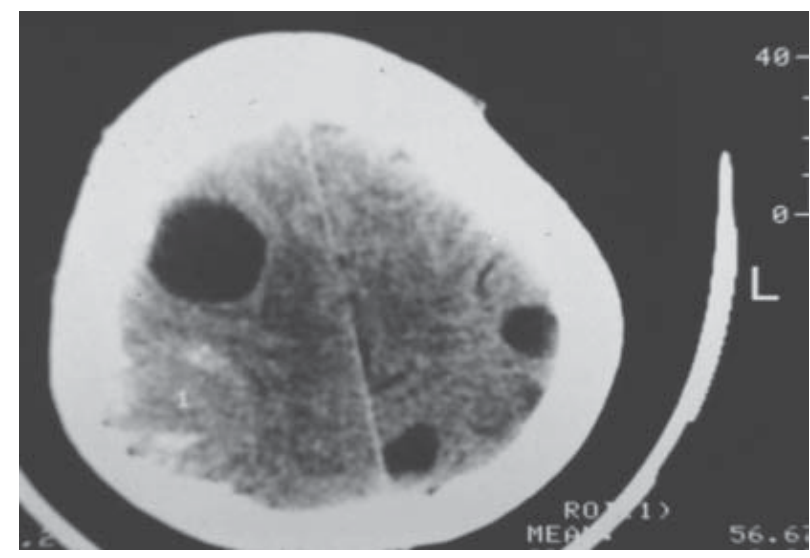

Figura 1. Tomografía axial computarizada simple de cráneo en corte axial; se observan múltiples vesículas de cisticercos en ambos hemisferios, sin edema cerebral asociado a los mismos. Se encuentra lesión parietal derecha, parcialmente calcificada, de $5 \times 4$ centímetros, que se origina en la duramadre.

1 Jefe del Servicio de Neurocirugía del Hospital General de León, Gto. Adscrito al Servicio de Neurocirugía del Hospital Ángeles León.

2 Médico especialista en Medicina de Rehabilitación. Hospital Angeles León.

Correspondencia:

Dr. Luis Gerardo Domínguez-Carrillo

Correo electrónico: Igdominguez@hotmail.com

Aceptado: 26-08-2015.

Este artículo puede ser consultado en versión completa en http:// www.medigraphic.com/actamedica

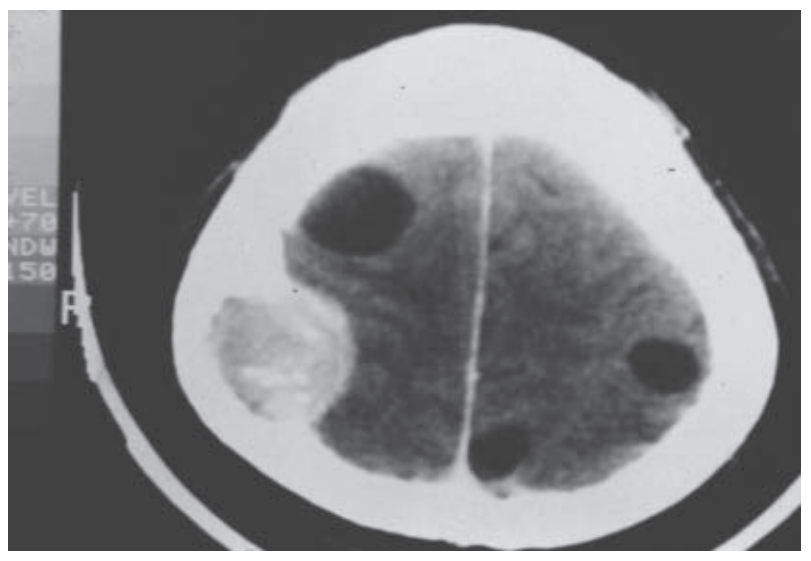

Figura 2. Tomografía axial computarizada de cráneo con contraste en corte axial, que muestra reforzamiento de la lesión parietal derecha de $5 \times 4$ centímetros; corresponde a meningioma en un sujeto masculino de 40 años de edad, asociado a cisticercos en etapa vesicular, sin edema cerebral.

contraste (Figura 2). Se realiza el diagnóstico de meningioma, cisticercosis vesicular múltiple y crisis convulsivas secundarias a meningioma por la ausencia de reacción inflamatoria. Se practica resección total del tumor con hueso afectado; se retiran varias vesículas de cisticercos que rodean el tumor. La evolución del paciente es satisfactoria; recibió tratamiento postoperatorio con esteroides, abendazol $15 \mathrm{mg} \times \mathrm{kg}$ de peso por día por tres semanas y difenilhidantoína sódica, así como programa de rehabilitación. Se le dio seguimiento por seis meses, donde se mostró libre de crisis convulsivas. Se dio de alta con recuperación total de la hemiparesia.

La asociación de cisticercosis y meningioma es extraordinaria, ya que los dos reportes existentes corresponden, uno, a individuo con dicha asociación más la presencia de adenoma hipofisiario ${ }^{1}$ y el otro al campo veterinario ${ }^{2}$ (a una res).

\section{REFERENCIAS}

1. Ramirez Mdel P, Restrepo JE, Syro LV, Rotondo F, Londoño FJ, Penagos LC et al. Neurocysticercosis, meningioma, and silent corticotroph pituitary adenoma in a 61-year-old woman. Case Rep Pathol. 2012; 2012: 340840. doi: 10.1155/2012/340840.

2. Bwangamoi O, Sachs R. Cerebral cysticercosis in two cows and the incidental finding of meningioma in one of them. Bull Epizoot Dis Afr. 1969; 17 (2): 223-229. 